\title{
Branko Mitrović
}

\section{Intentionalism, Intentionality and Reporting Beliefs}

\author{
Originally published in History and Theory, 48 (2009), 180-198.
}

[ABSTRACT] The dominant view of twentieth century analytic philosophy has been that all thinking is always in a language; that languages are vehicles of thought. In recent decades, however, the opposite view, that languages merely serve to express language-independent thought-contents or propositions, has been more widely accepted. The debate has a direct equivalent in the philosophy of history: when historians report the beliefs of historical figures, do they report the sentences or propositions that these historical figures believed to be true or false? In this paper I argue in favor of the latter, intentionalist, view. My arguments mostly center on the problems with translations that are likely to arise when a historian reports the beliefs of historical figures who expressed them in languages other than the one in which the historian is writing. In discussing these problems the paper presents an application of John Searle's theory of intentionality on the philosophy of history. [ABSTRACT ENDS]

The debate between the view that all thinking is verbal and always in a language and the view that human beings think independently of any language (using their languages merely in order to express their thoughts) has had an extensive history in the philosophy of language for the past hundred years. It also has numerous implications for the philosophy of history, where the problem can be stated in general terms as the question of whether a historian, when reporting the beliefs of historical figures, reports the thought-contents (conceived as independent of the language in which they were articulated) or the sentences that these people believed to be true or false. Among English-speaking historians of philosophy, the latter view was promoted by Arthur Danto, the former by Quentin Skinner and Mark Bevir. Both positions are reflected in specific problems of history-writing, such as, for instance, the question whether and how a historian can report the beliefs of historical figures who articulated them in languages different from the language in which the historian is writing. Both positions also fundamentally rely on the assumption that it is possible and legitimate to provide translations of sentences from one language to another when reporting the beliefs of historical figures; but, as we shall see, they are not on equal footing when it comes to explaining what counts as a legitimate translation.

This paper explores the implications that these two views on the role of language in human thinking have for the philosophy of history. It will show that the view that all human thinking is verbal is not compatible with some fundamental and standard practices of history-writing. Thus, the paper can be seen as a contribution to the debate about intentionalism in history-writing. It argues in favor of the 
intentionalist approach by introducing new arguments derived from the philosophy of language, while at the same time proposing a formulation of the intentionalist position that relies on John Searle's philosophical elaboration on the concept of intentionality.

\section{Intentionalism versus sententionalism}

According to the view that all thinking is verbal, an ordinary language such as French or Russian is a vehicle of thought; there can be no thoughts independent of their articulation in a language. This means that only properly formed sentences of ordinary languages (but not thought-contents, conceived of as independent of any language) can be said to be true or false; human beliefs are then always the beliefs that a certain sentence is true or false. When historians report the beliefs of historical figures, they report the sentences these individuals believed to be true or false-throughout this paper, I will refer to this view as sententionalist. Vice versa, according to the opposing view, languages are mere vehicles of human communication and individuals use them in order to convey the contents of their thoughts-while thought-contents themselves are independent of the language in which they may be articulated. It is consequently the contents of human thoughts that are properly said to be true or false; sentences are true or false only insofar as they articulate true or false thought-contents-and beliefs are always beliefs that some thought-contents are true or false. Historians endeavor to reconstruct and report the thought-contents that historical figures believed to be true or false-and I will refer here to this latter view as intentionalist. The sentence "Tom believes that Cicero denounced Catiline" says, according to the sententionalist account, that Tom believes that the sentence "Cicero denounced Catiline" is true. On the intentionalist account, the same sentence says that Tom believes that the thought-content expressed by the sentence "Cicero denounced Catiline" is true.

Talking about intentionalism in history-writing means relying on some understanding of intentionality-and in the main, my analysis here follows John Searle's account in his book Intentionality. ${ }^{1}$ I believe that Searle's theory of intentionality has much to say about the philosophy of history, and particularly in the context of the recent revival of interest in intentionalism. Following Searle, in this article I assume that propositions, the contents of thoughts believed to be true or false, are formulated independently of any language. Postulating such propositions does not imply any heavy metaphysical apparatus - as Searle points out, if two persons share the same thought, the sense in which they have an abstract entity in common "is the utterly trivial sense in which, if I go for a walk ... and you go for the exactly same walk, we share an abstract entity, the same walk, in common" (198). Propositions thus understood are the contents and not the objects

\footnotetext{
${ }^{1}$ John Searle, Intentionality (Cambridge, UK: Cambridge University Press, 1983). For Searle's own summaries of his position, see his articles "Intentionality 1" in A Companion to the Philosophy of Mind, ed. Samuel Gutenplan (Oxford: Blackwell, 1998), 379-386, and "Intentionality and the Use of Language," in Meaning and Use, ed. Avishai Margalit (Dordrecht: Reidel, 1976), 181-197.
} 
of beliefs. ${ }^{2}$ To state the object of a belief - that is, its intentional object-is to say what the belief is about. The object of Tom's belief that Cicero denounced Catiline is a certain event that occurred in the Roman Senate and not some shady intermediary between Tom and the event. It is impossible to have beliefs without content, and the intentional content of a belief specifies the conditions that need to be fulfilled for that belief to be satisfied. If Peter believes that the present-day Prime Minister of England has a moustache, then he has a false belief-that is, one whose conditions of satisfaction are not fulfilled. ${ }^{3}$

Searle often rightly emphasizes that speech acts may sometimes be made and propositions expressed without any intention to communicate these propositions to anyone. However, history is almost always written for a certain public-historians writing for no one are rare. Even a historian taking notes in an archive is writing for his or her later use; for example, the abbreviations he or she uses may not be comprehensible to someone else, but need to be comprehensible later to that same historian. Throughout this paper I consistently assume that history-writing is always performed with an intention to communicate.

The core arguments of the paper are deeply rooted in some of the most widely debated problems of the philosophy of mind and its branch, the philosophy of language. The paper has profited immensely from these debates and, insofar as it makes the presentation of my arguments easier to follow, I shall make an effort to describe this wider context of my arguments, in order to make them more easily accessible to readers less acquainted with analytic philosophy.

\section{Words and thoughts}

Introspection inclines some people to assume that they think in words-whereas others believe, also on the basis of introspection, that their thinking is preverbal. Various arguments that belong to the realm of armchair psychology can be stated in support of one view or another. Those who believe that thinking precedes its verbal articulation may base their opinion on experiences such as occasional difficulties in finding the suitable word to express a certain thought or recognizing a person without being able to remember the person's name. But this argument can be answered by saying that the process of finding a suitable word is the process of formulating a thought. Similarly, it may be argued that animals or prelinguistic infants are able to think and have beliefs. ${ }^{4}$ But it is possible to answer this argument by saying that thinking in a language is indeed particular to grown-up humans. It may also be argued that human beings are able to differentiate among numerous properties of objects (such as nuances of colors) without being able to name them. This argument can be answered by saying that such differentiation really occurs as part of perception and does not count as thinking. Visual imagination, for instance, may be stated as a particularly prominent example of a nonverbal mental process: it

\footnotetext{
2 Searle, Intentionality, 18.

3 Ibid., 16-21.

${ }^{4}$ For a summary and discussion of research on this topic, see José Luis Bermúdez, Thinking without Words (Oxford: Oxford University Press, 2003).
} 
may be argued that its operation is necessary for solving complex, threedimensional, geometrical problems and that it should therefore count as thinking. Some philosophers, such as Willard van Orman Quine, however, have denied that there is such a thing as visual imagination. ${ }^{5}$ Michael Dummett, another strong proponent of the view that all thinking is verbal, answered the dilemma about the status of visual imagination by saying that it does not count as thinking. ${ }^{6}$ Such an approach is open to the criticism that it first excludes nonverbal mental processes from the definition of thinking and then claims that all thinking is verbal.

The view that all thinking is verbal has had a complex history in twentiethcentury analytic philosophy. It is fair to say that during the period of the "linguistic turn" this was the dominant view, but it has fallen out of fashion with the rise of the "cognitive turn."7 The view was promoted by a number of prominent analytic philosophers, such as Quine, Dummett, and Gilbert Harman. ${ }^{8}$ Dummett even identified analytic philosophy with the rejection of the view that there can be nonverbal thoughts. ${ }^{9}$ (In fact, the idea that all thinking is verbal goes back at least to Johann Gottfried Herder. ${ }^{10}$ ) Donald Davidson tried to argue that neither language

\footnotetext{
5 "The Parthenon is visible; the Parthenon-idea is invisible. We cannot imagine two things more unlike, and less liable to confusion, than the Parthenon and the Parthenon idea." Willard van Orman Quine, "On What There Is," in From a Logical Point of View (New York: Harper and Row, 1961), 2. The formulation leaves no space for the assumption that the idea of the Parthenon could be an analogous visual representation of the building.

${ }^{6}$ Michael Dummett, "Language and Communication," in his book The Seas of Language (City: Publisher, Year) 166-187, 170. More precisely, Dummett argued that a thought is capable of being true or false; a visual image, imagined or given in sensation, is true or false only in relation to external reality, whereas that which renders an image an image of an object is the concomitant thought to the effect that it represents that object. However, it is far from clear that all thoughts have to be true or false.

7 Bermúdez, Thinking without Words, 3-5.

8 See the essays "Language: Thought and Communication" and "Language Learning" in Gilbert Harman, Reasoning, Meaning and Mind (Oxford: Clarendon Press, 2005), 166-182 and 183-191. Both essays are inconclusive. The first essay starts with the observation that the "view that language is used primarily in thought, need not imply that all or even most thinking or theorizing is in some natural language" (167), though this is precisely what Harman subsequently attempts to argue. The second essay concludes with the observation that it is impossible to say whether the idea that we first think and then translate these thoughts in a language is better than the view that all thinking is in a natural language (191). Quine's view was that only material, physical token-sentences could be properly regarded as truth-bearers, so he was consequently obliged to argue that only such sentences can be believed to be true or false-in other words, that there can be no non-verbal thought-contents that can be true or false. In his article "Meaning in Linguistics" (in Quine, From a Logical Point of View, 47-64, 61), he stated that "there is in principle no separating language from the rest of the world.... It is not clear even in principle that it makes sense to think of words and syntax as varying from language to language while the content stays fixed...." For Dummett, see, for instance, his essay "Language and Communication," cited above, as well as the essay "What Do I Know When I Know a Language," in Dummett, The Seas of Language, 94-105.

9 "The whole analytical school of philosophy is founded on the rejection of this conception, first clearly repudiated by Frege.," Dummett, "What Do I Know," 97. See also a similar formulation in his "Language and Communication," 171.

${ }^{10}$ Johann Gottfried Herder, Abhandlung über den Ursprung der Sprache [1778] (Stuttgart: Phillip Reclam, 1966). Herder denies that sensation depends on language (85), but he nevertheless makes the point that "Kette von Gedanken wird eine Kette von Worten" (85) and "kein Zustand in der
} 
nor thought have conceptual priority over each other, but ultimately the way he phrased his arguments can be taken to suggest that he assumed the priority of language. ${ }^{11}$ As the opponents of the priority of language, one should mention Paul Grice, Jerry Fodor, Jerrold Katz, and John Searle. In his 1957 paper "Meaning," Grice argued that for an X to mean something, it must have been uttered with the intention of inducing a certain belief, and the utterer must have intended an "audience" to recognize the intention behind the utterance. ${ }^{12}$ This intention, he says, is only rarely linguistically formulated. ${ }^{13}$ In Fodor's view, the sentences that we encounter in our conscious thinking often suffer from ambiguities-for example, two different thoughts can be expressed by the sentence "Visiting philosophers can be unpleasant" - whereas "thought needs to be ambiguity free." 14 Ambiguities result in difficulties when it comes to formulating an efficient theory of translation between languages - an important point in the context of this article, since a historian often needs to describe the beliefs of individuals who did not use the language in which he or she is writing.

It is fair to say that the authors who advocate the view that all thinking is verbal have failed to formulate systematic views on the problem of translation from one language to another. ${ }^{15}$ According to Dummett, translation is a mechanical process that can be performed by a computer, and a translator does not actually need to understand a sentence in order to translate it. ${ }^{16}$ Quine's discussion of "radical translation" can only be of marginal interest for us here, because it deals

menschlichen Seele sei, der nicht wortfächig oder würklich durch Worte der Seele bestimmte werde" (86); “Der Mensch empfindet mit dem Verstande und spricht, indem er denket" (86). For a general history of the view that all thinking is verbal, see Michael Losonsky, Linguistic Turns in Modern Philosophy (Cambridge, UK: Cambridge University Press, 2006).

11 Donald Davidson, "Thought and Talk," in Donald Davidson, Inquiries into Truth and Interpretation (Oxford: Clarendon Press, 2001), 155-170. In the article, Davidson says that he wants to defend the no-priority view, and he is indeed commonly cited as arguing that position. (See for instance Martin Davis, "Foundational Issues in the Philosophy of Language," in The Blackwell Guide to the Philosophy of Language, ed. Michael Davitt and Richard Hanley [Malden, MA: Blackwell, 2006], 19-40, 30.) But throughout the article he argues that it is impossible to have thoughts without being a interpreter of the speech of another (160), and insists that it is sentences (and not thoughts) that are believed to be true (161). The article was indeed interpreted by Searle as asserting the primacy of language over thought; see John Searle, "Animal Minds," Midwest Studies in Philosophy 19 (1994), 206-219.

12 Paul Grice, "Meaning," Philosophical Review 66 (1957), 382. See also his “Utterer's Meaning and Intention," Philosophical Review 78 (1969), 147-177, and also Studies in the Way of Words (Cambridge, MA: Harvard University Press, 1989).

13 Grice, "Meaning," 387.

14 Jerry Fodor, "Do We Think in Mentalese," in In Critical Condition: Polemical Essays on Cognitive Science and the Philosophy of Mind (Cambridge, MA: MIT Press, 1998).

15 One should mention Christopher Gauker, Thinking Out Loud (Princeton: Princeton University Press, 1994), 271-292, as one of the few authors who has attempted to discuss translating from one language into another from the sententionalist point of view. But he fails to address problems I present later in this article.

16 "In principle, we can imagine a person-or a very skilfully trained computer-able to translate between two languages without understanding either.” Dummett, “What Do I Know," 98. 
with the hypothetical case of creating translation manuals for languages spoken by communities that have had no interaction with each other in the past. ${ }^{17}$

Among philosophers of history, the sententionalist position was promoted by Arthur Danto in his Narration and Knowledge. ${ }^{18}$ Danto defines one of the central topics of his book, "narrative sentences," as the sentences that include reference to events later in time than the events they are about. Such sentences are, in his view, cognitively inaccessible to the observers of the events they describe. His favorite example is:

The Thirty Years' War started in 1618.

which, he argues, could not have been known to be true before $1648 .{ }^{19}$ (Danto's is not the trivial point that nobody before 1648 could have known how long the war would continue, but that the name of the war would have been incomprehensible.) In order to make this claim, one must assume that only sentences can be true or false, and not the propositions these sentences express. The alternative view would be, for instance, that the above sentence articulates a proposition that a person living in 1625 would have known to be true. Such a person would have understood the above sentence if it had been expressed differently-for example, as referring to the war that was currently going on in Germany. Events can be named in various ways, and only some names are known to some individuals. The fact that people of a certain period could not have understood a sentence that contains a phrase incomprehensible at the time does not necessarily mean that these people could not have believed that the proposition the sentence expresses was true or false. Aquinas, for instance, would not have known that the following sentence is true:

Aristotle was a disciple of Plato.

simply because it is in English. But he would have known that the proposition this sentence expresses was true. Similarly, one can imagine the population of a Neolithic settlement placed near a lake discovering a current in the lake that enabled them to circumnavigate it. A modern archaeologist may describe this by saying:

They discovered that the current goes clockwise.

This certainly does not mean that the Neolithic inhabitants of the settlement knew of clocks. But it does imply that they were aware of the truth of the proposition expressed in modern English using the sentence: "The current goes clockwise."

\footnotetext{
17 Willard van Orman Quine, Word and Object (Cambridge, MA: MIT Press, 1960), 28 and then esp. 68-79. But see Searle's critique of this view in John Searle, "Indeterminacy, Empircism and the First Person," Journal of Philosophy 84 (1987), 123-147.

${ }_{18}$ Arthur Danto, Narration and Knowledge (New York: Columbia University Press, 1985).

${ }^{19}$ Ibid., 152.
} 
If a sententionalist historian is going to report the beliefs of individuals who expressed them in languages other than the one in which he or she is writing, it will be necessary to provide translations-and if the sententionalist account of historywriting is going to be credible, it must include a satisfactory account about translations from one language to another. "Satisfactory" means here that the account should be able to specify, starting from the assumption that all thinking is verbal, what it is that a historian provides when he or she provides a translation of a sentence a historical figure believed to be true or false-and, at the same time, that this account must not contradict standard practices of history-writing.

A position very different from Danto's can be found in Quentin Skinner's article "Language and Social Change." ${ }^{20}$ Skinner strongly emphasized the difference between concepts and the words that express them. ${ }^{21}$ Skinner's view is that in order to possess a concept, one need not understand the correct application of a corresponding term. Milton, for instance, he says, thought that originality was important, although the word "originality" came into use only a century after his death; he therefore talked about "things unattempted." (This example may indeed present a problem for Danto: if we cannot ascribe to a person living in 1625 the belief that the Thirty Years' War started in 1618, by analogy we cannot say that Milton believed that originality was important.) Skinner also observes that the possession of a concept is standardly signaled by the employment of a corresponding term, but "standardly" here means neither necessarily nor sufficiently.

\section{Beliefs and language}

A historian may need to write a sentence such as:

Aquinas believed that the soul is immortal.

\footnotetext{
20 Quentin Skinner, "Language and Social Change," in Meaning and Context: Quentin Skinner and his Critics, ed. James Tully (Princeton: Princeton University Press, 1988), 118-132.

${ }^{21}$ Gad Prudovsky's criticism of Skinner's position as “licensing an absolute priority of talk over thought" is thus not justified. (Gad Prudovsky, "Can We Ascribe to Past Thinkers Concepts They Had no Linguistic Means to Express," History and Theory 36 [1997], 28.) Whereas in "Meaning and Understanding" (Tully, ed., Meaning, 29-67) Skinner acknowledges Quine's views (note 155 on p. 300); throughout the essay, on a number of occasions he makes a clear distinction between the concept and word, thought-content and its articulation: "When they spoke of 'egoism,' what they meant was something much more like what we should mean by solipsism" (51); he criticizes Lovejoy's study of the history of words: "For the words denoting the idea may be used, ... with varying and quite incompatible intentions" (55). The only section in the essay that can be interpreted along sententionalist lines is when he excludes "the possibility that an acceptable account of an agent's behaviour could ever survive the demonstration that it was itself dependent on the use of criteria of description and classification not available to the agent himself." The use of the word "description" in this context may support a sententionalist reading: but equally well, a "description" may stand for the way a mental content represents a certain thing or event.
} 
But since Aquinas did not speak English he could not understand the sentence "The soul is immortal" nor believe that it was true. The sententionalist position will argue that the above sentence should be reformulated into:

Aquinas believed that the Latin sentence whose English translation is "The soul is immortal" is true.

and suggest that when reporting beliefs, one should rely on the rule:

Principle of translation: Version 1

When reporting beliefs of individuals who expressed their beliefs in languages other than the one in which a historian is writing, the historian may (should) provide legitimate translations of the sentences these individuals believed to be true (or false).

The critical phrases are "languages other than the one in which a historian is writing" and "legitimate translations." There is no clear criterion to decide what counts as one and the same language-which notoriously leads to endless debate about whether Dutch and Flemish, Serbian and Croatian, standard Italian and Sardinian are different languages or mere dialects of the same language. Similarly, though one normally assumes that Chaucer wrote in English, we may need to translate his sentences in order to understand them. At the same time, even when we deal with languages that are normally accepted to be different, some of them may be so similar that their speakers may understand each other and regard translation as unnecessary. Vice versa, even native speakers may need translations when sentences in their own contemporary language and their own dialect contain phrases that are incomprehensible to them. Probably motivated by such problems, Saul Kripke once stated that translations were always between idiolects-but he did not define this last term. ${ }^{22}$ In any case, we need a clear criterion stating when a historian may or should provide a translation. It is therefore reasonable to abandon attempts to define the need for translation by relying on the concept of a different language and reformulate the above principle into:

Principle of translation: Version 2

When reporting the beliefs of individuals who expressed their beliefs using sentences that contain words or phrases incomprehensible to the public the historian is writing for, a historian may (should) provide legitimate translations of the sentences these individuals believed to be true (or false).

(This last formulation still does not allow us to say, in English, that Milton believed that originality was important, since modern readers would still understand his phrase about "things unattempted.")

The second critical phase is "legitimate translations." Let us consider whether and how the sententionalist position can explain translation in a way that

22 Saul A. Kripke, “A Puzzle about Belief," in Margalit, Meaning, 263. 
corresponds to standard practices in history-writing. The sententionalist position assumes identity between the contents of human beliefs and their verbal articulations. Verbal articulations of that which humans believe to be true or false are not conceived of as mere expressions of nonverbal propositions. The assumption is that there can be no nonverbal propositions that could be believed to be true or false. Only sentences can be believed to be true or false, and sentences refer, truly or falsely, to material objects, their dispositions and properties. As a result, sentences do not say how these objects, their dispositions and properties are thought about independently of the verbal articulation of these thoughts. Consider the following sentences:

The Morning Star is always visible close to the Sun.

The Evening Star is always visible close to the Sun.

Phosphorus semper prope Solem visibilis est.

Hesperus semper prope Solem visibilis est.

They are all true, have the same reference, and describe the same property of the planet Venus. Nevertheless, it is the first and third on the one hand, and the second and fourth on the other, that are acceptable as each other's translations from English to Latin and vice-versa. It may seem possible to argue that the sententionalist point of view cannot make this distinction: an English and a Latin speaker would know about the property only as verbally described in a certain way. Knowing something is knowing that a certain sentence is true. It seems unclear how, from the sententionalist point of view, one could claim that the third sentence is a better Latin translation of the first sentence than the fourth. (From the intentionalist position, the first and the third on the one hand, and the second and the fourth on the other, express the same propositions, since they have identical conditions of fulfillment.)

However, this argument against sententionalism can be answered by saying that legitimate translations are established by means of translation manuals (dictionaries and syntactic rules) that enable us to say that the first and the third, and the second and the fourth, of the above sentences are each other's legitimate translations. The process of translation, from this point of view, does not result in a sentence that conveys the intended meaning, but, rather, it manufactures a sentence in another language, according to certain translation rules. This argument was presented, for instance, by Quine in order to account for the fact that translation was possible between languages that have not grown in absolute isolation from each other. He argues that "containment in a continuum of cultural evolution facilitated translation of Hungarian into English." 23 This produces, in his view, "an illusion that our so readily intertranslatable sentences are diverse verbal embodiments of some intercultural proposition or meaning, when they are better seen as the merest

${ }^{23}$ Quine, Word and Object, 76. 
variants of one and the same cultural verbalism."24 Note that according to this account what constitutes a good translation is established exclusively on the basis of a set of social (cultural) norms which drive the behavior of translators as members of certain groups - it is defined independently of any act of comprehension that the translation may enable.

One important problem is, however, that a translation of a sentence always depends on the wider context in which the sentence was used; a translation must treat the original text holistically. Quine's explanation of the process of translation assumes that the translation of a sentence is established on the basis of the rules defined by dictionaries and grammar. These rules, Quine says, are the products of cultural evolution. However, a dictionary will typically give more than one English word as the translation of a word in another language, and by relying strictly on dictionaries and grammatical rules we are often likely to finish up with a number of English sentences as equally valid translations of a given sentence in another language. Some of these sentences may be perfectly meaningless and others meaningless in the given (but conceivably meaningful in some other) context. Typically, only one or very few of them can be accepted as meaningfully participating in the given context. A Quine-style theory of translation would consequently have to specify the rules that would enable us to differentiate between legitimate and illegitimate translations in specific contexts. The only way to do this would be to enumerate, for every sentence of a given language, all contexts in which that sentence is to be translated with a specific English sentence. Quite likely, in many cases, such lists would be impractically long or infinite ${ }^{25}$ But the real problem is that such lists simply do not exist, and translators work without them-a practice that a Quine-style theory of translation cannot explain. We shall see later how the intentionalist approach accounts for the concept of legitimate translation and especially translation in context.

The sententionalist position faces problems with homonyms as well. Quine himself, in his Philosophy of Logic, admitted that his philosophy of language faces difficulties when it has to deal with homonyms even within one and the same language: it cannot explain, for instance, when the English words drive and lane can substitute for each other and when not. ${ }^{26}$ A "legitimate translation" sententionaliststyle would imply that for every sentence that a non-English speaking person believes to be true or false, there exists (at least) one corresponding English sentence that is accepted as its "legitimate" translation under normal translation

\footnotetext{
24 Ibid.

25 They will not always be infinite. For instance, in the case of sentences that contain some Greek and Latin, words appear only a limited number of times in the entire corpora of Greek and Latin writings we have inherited from classical antiquity.

26 Willard van Orman Quine, Philosophy of Logic (Englewood Cliffs, NJ: Prentice Hall, year), 18. Quine is actually trying to provide an account of the fact that when such words are substituted in a sentence, they sometimes fit and sometimes disturb the grammatical structure. Since the traditional classification of words according to the parts of speech cannot be made without relying on the sense of the word (drive is sometimes a noun and sometimes a verb), he rejects it and proposes a new system whereby there would be a great many types of words, and some categories would contain only one or a few words. In any case, this amounts to the admission that on the sententionalist account one cannot explain when drive can be substituted by lane in a sentence and when it cannot.
} 
practices. But, when establishing the legitimate translation into English of a sentence written, for example, by Aquinas, we are likely to face situations in which there is more than one equivalent sentence in English. Sometimes these English equivalents may even be contradictory. In such a situation a historian working from the intentionalist position may assume that Aquinas did not express clearly the proposition he intended to express. It will not be necessary to assume that Aquinas had contradictory beliefs-it is often more likely that Aquinas did not clearly state which of a number of propositions his sentence expresses he believed to be true. It may still be assumed-and in most cases it will be reasonable to assume-that Aquinas believed only one of them to be true. Arguably, this is also the way historians of philosophy would react in this situation; one does not assume that great thinkers subscribed to contradictory beliefs whenever their statements can be interpreted in more than one way. This highly plausible interpretive assumption is, however, not available to a sententionalist historian. From the sententionalist point of view, there are no extra-linguistic propositions that are merely articulated in sentences. If Aquinas believed that a Latin sentence that has three mutually contradictory English equivalents was true, then he had contradictory beliefs-and it is pointless to ask which of the three sentences articulates his real belief. ${ }^{27}$

Moreover, some English sentences may translate more than one Latin sentence written by, say, Aquinas. From the sententialist point of view, in such a case it will be necessary that all the Latin sentences that a single English sentence translates are either true or false in Aquinas's view. Imagine, for instance, that a certain English sentence " $E$ " translates five co-referential Latin sentences. (There is nothing to prevent this in Quine's account. According to the intentionalist account this will happen if these sentences express the same proposition.) Aquinas may, however, have understood the first, second, and fourth sentences and believed them to be true, but did not understand the third and fifth, and consequently, did not believe them to be true. Simply, the third and the fifth sentences may have contained words or phrases unknown to him-which may also happen to any native speaker of any language. Since $\mathrm{E}$ is the English translation of all five Latin sentences, and since according to the sententionalist account, beliefs are always beliefs that certain sentences are true or false, we have to say that Aquinas believed that $\mathrm{E}$ was true and he did not believe that $\mathrm{E}$ was true. This kind of situation cannot arise if we start from the intentionalist position, since what we report in that case is the proposition an individual believed to be true, regardless of the fact that some of its articulations were not known to a specific individual. According to the intentionalist account, it will require a separate sentence to say that a certain person did or did not know (or believe) that the proposition that is expressed using the English sentence E can be expressed with the Latin sentence L. Stating beliefs about available verbal

\footnotetext{
27 The sententionalist position here cannot be defended by referring to authors such as Quentin Skinner, who criticize the tendency to postulate the coherence of the views of various authors whose works are studied by historians. The sententionalist claim is of much wider scope; it assumes that always when multiple contradictory translations (into any language) are possible, the historical figure necessarily had contradictory beliefs.
} 
articulations of a certain proposition is understood to be different from saying that a person did not believe that proposition to be true or false.

\section{Beliefs and thoughts}

The intentionalist account of reporting the beliefs of historical figures assumes that historical figures thought and formed beliefs about various intentional objects. The propositions they entertained were true or false representations of intentional objects, and these individuals believed that these propositions were true or false. Historical figures also expressed their beliefs in languages available to them. On the basis of such expressions, a historian has to

a) form beliefs whose intentional objects are the beliefs of historical figures and then,

b) express them in a way that will successfully enable his or her readers to form beliefs about his or her beliefs about the beliefs of historical figures. (This will typically result in readers adopting the same beliefs about the beliefs of historical figures as the historian.)

A person A may thus have a series of beliefs that propositions $\xi_{1}, \xi_{2} \ldots \xi_{n}$, which are all satisfied by the same intentional object, are true or false (for example, that the greatest Roman orator denounced Catiline, that the author of De natura deorum denounced Catiline, that the author of De divinatione denounced Catiline, and so on). For some $\xi_{\mathrm{i}}$ s this person will know a number of articulations in one or more languages. "To know an articulation of a proposition" means either to be able to express this proposition in a language or to understand it when it has been expressed by another individual. For instance, one and the same proposition can have the following articulations: "Cicero denounced Catiline," "Catiline was denounced by Cicero," "Cicero Catilinam detulit," and so on. To formalize this account one may use a table:

$\begin{array}{llll}\xi_{1}, & \xi_{2} & \ldots & \xi_{\mathrm{n}} \\ \mathrm{a}_{11} & \mathrm{a}_{21} & \ldots & \mathrm{a}_{\mathrm{n} 1} \\ \mathrm{a}_{12} & \mathrm{a}_{22} & \ldots & \mathrm{a}_{\mathrm{n} 2} \\ \ldots & \ldots & \ldots & \ldots \\ \ldots & \mathrm{a}_{2 \mathrm{p}} & \ldots & \ldots \\ \mathrm{a}_{1 \mathrm{q}} & - & \ldots & \ldots \\ - & - & \ldots & \mathrm{a}_{\mathrm{nr}}\end{array}$

The upper row lists propositions about the same intentional object: $\xi_{1}, \xi_{2} \ldots \xi_{\text {n }}$ which a person A believes to be true or false. Consider for instance the following two sentences:

The greatest Roman orator denounced Catiline. The author of De natura deorum denounced Catiline. 
They express two different propositions about the same intentional object (an event that occurred in the Roman Senate). The two propositions expressed by these two sentences are satisfied by the same event, but the lists of conditions that need to be fulfilled for each of them to be satisfied are different. However, the sentences "Cicero denounced Catiline," "Cicero Catilinem detulit," and "Catiline was denounced by Cicero" express one and the same proposition, only using different words. They are articulations of the same proposition, and individuals may have the same thoughtcontents even if they do not speak the same language.

Each proposition $\xi$ in the above table has a number of verbal articulations $\mathrm{a}_{\mathrm{i}}$ known to the person $\mathrm{A}$, and these articulations may be in different languages. In other words, A knows $q$ articulations of the proposition $\xi_{1}$, p articulations of $\xi_{2}$, and so on. It is at the same time possible that $A$ has a belief that a proposition $\theta_{\mathrm{k}}$ is false without knowing that the conditions of satisfaction of $\xi_{\mathrm{i}}$ and $\theta_{\mathrm{k}}$ are fulfilled by the same intentional object and are both true. In that case A will have contradictory beliefs.

If a person $A$ knows that $\mathrm{a}_{\mathrm{ij}}$ articulates $\xi_{\mathrm{i}}$, then $\mathrm{A}$ can use $\mathrm{a}_{\mathrm{ij}}$ in order to convey $\xi_{\mathrm{i}}$ to person $\mathrm{B}$, if $\mathrm{B}$ understands $\mathrm{a}_{\mathrm{ij}}$. Translating between languages consists of understanding the proposition $\xi_{\mathrm{i}}$ expressed using the articulation $\mathrm{a}_{\mathrm{ij}}$ in one language and then expressing the same content using another articulation $\mathrm{a}_{\mathrm{ik}}$ in another language in a way that will convey the same thought-content to those the translation is intended for. Insofar as it is pointless to make a translation if one does not believe that it will convey a certain proposition to the public it is intended for, a translation is always a result of the translator's belief that a certain combination of words will convey a certain intentional content to a certain group.

The problems that we have seen that the sententionalist approach faces when it has to explain the legitimacy of translations become trivial when approached from the intentionalist point of view. In the case of homonyms, if a dictionary says that a certain word can be translated in two different ways, the intentionalist account would say that the correct translation is the one that accurately conveys the proposition intended by the person who stated the sentence to the public the translation is intended for (and if an ambiguity was present already in the original act of communication, then it is desirable, though not always possible, to reproduce the ambiguity as well). The fact that the translation has to convey the same proposition(s) as the original text also explains the need to treat translations holistically and to translate sentences in a way that relates to the specific context. First, translating does not always work sentence-by-sentence, nor is it always the case that a single sentence expresses a single proposition. A good style in many European languages requires long sentences, typically expressing more than one proposition, while, for the last century at least, what is recognized as good English prose has been increasingly marked by short sentences. As a result, a longer sentence from another language, expressing more than one proposition, may often have to be broken down into smaller sentences, each expressing singular propositions, in the process of translation into English.

Furthermore, the context in which the sentence is used often substantially contributes to specifying the proposition the sentence conveys. It is important to 
bear in mind that the totality of propositions a text conveys (the conditions of satisfaction it specifies) need not be identical with the sum of propositions (their conditions of satisfaction) of all the individual sentences that make up the text. Some eastern European languages use a phrase that literally translates into English as "to rediscover warm water" in a way that when a text containing this sentence is translated into English, depending on the context, the sentence may sometimes need to be translated literally, and sometimes using the English phrase "to re-invent the wheel." It would certainly be beyond the scope of this paper to attempt to present even a brief summary of intentionalist hermeneutics and the theory of translation, but one can nevertheless try to describe here, in general terms, the understanding of the legitimacy of translation that follows from the discussion that has been presented here. The intentionalist theory of translation has been discussed here only on the basis of simple examples (e.g. sentences about Cicero or Venus); more complex texts are likely to introduce additional specific problems and requirements. ${ }^{28}$ Nevertheless, in general, an important aspect of the intentionalist theory of translation would be:

A translation of a text is legitimate if it conveys to the public it is intended for the same totality of propositions (has the same conditions of satisfaction) as the totality of propositions (conditions of satisfaction) expressed in the original text. 29

It follows that producing a legitimate translation is often a task difficult to achieveand this is indeed the case with translations.

\section{The sententionalist account of belief reporting}

It is a commonplace that sentences that report beliefs may change truth-value if the phrases used in the description of the content of belief are replaced with coreferential ones. Quine's much cited example is:

Tom believes that Cicero denounced Catiline.

If we now replace "Cicero" in this sentence with "Tully" we get:

\footnotetext{
${ }^{28}$ E.g. see the next note.

${ }^{29}$ I exclude from this the propositions that state the author believed that a certain sentence can or should be used in order to express the proposition he or she was expressing. In other words, when reading a text, we are reading sentences that express:

a). certain propositions

b). implicitly also the author's belief that these proposition should be expressed using that specific sentence.

These latter beliefs also pertain to certain propositions, and these latter propositions are normally not reproduced in a translation. However, there are exceptions: a translator may want to preserve some aspects of the original expression by retaining a technical term or using a cognate from a language into which he or she is translating.
} 
Tom believes that Tully denounced Catiline.

which, Quine points out, may not be true since Tom may not know that Cicero and Tully are one and the same person. According to the sententionalist position, beliefs are conceived of as attitudes to sentences since only sentences are assumed to be true or false. In this case, Tom does not believe that the sentence stating that Tully denounced Catiline is true. From the same point of view, it would be impossible to say that Tom actually does believe that Tully denounced Catiline but that he merely does not know that Tully is another name for Cicero.

When Quine has to explain how we know whether the above sentences have the same truth-value, he consistently refers to Tom's assenting to or denying them..$^{30}$ Singular acts of verbal behavior (that is, assent or denial), according to his view, are sufficient to establish what a person believes. Saul Kripke's disquotational principle explicitly formulates this approach:

If a normal English speaker, on reflection, sincerely assents to ' $p$ ', then he believes that ' $p$ '. ${ }^{31}$

Kripke accompanied this formulation with a series of disclaimers, including the requirement that the person assenting must be acting "sincerely," which excludes "mendacity, irony, acting and the like." 32 Ultimately this can only mean that the disquotational principle will be of little use in the philosophy of history. A historian, in his or her work, constantly deals with lack of sincerity thus defined. The disquotational principle can only be a recipe for poor scholarship when it comes to establishing the beliefs of historical figures. Singular acts of assenting or denying always have to be understood in the context in which they were made, in comparison with other statements by that same historical figure considered in their own context, his or her actions, interests, and so on. The rejection of the disquotational principle means that the philosophy of history in one important aspect of belief-reporting cannot follow the path of mainstream philosophy of language. This has nothing to do with the intentionalism-sententionalism debate. A sententionalist historian, who assumes that people think in the form of sentences, and believe that sentences are true or false, will be perfectly aware that historical research cannot get very far if it assumes the absolute sincerity of historical figures. Searle's view, that when reporting a person's beliefs one should not look "at the sentences he utters, [but] look at the total Intentional content in the man's head" seems a much more plausible approach in historical research. ${ }^{33}$ The sententionalist historian will most likely revise this dictum by assuming that it is always and only sentences that can be "in the man's head," but is as unlikely to rely much on the disquotational principle as does his or her intentionalist colleague.

\footnotetext{
${ }^{30}$ As Quine himself explained, because Tom may insist: "Tully did not denounce Catiline. Cicero did." See Quine, Word and Object, 148.

${ }^{31}$ Kripke, "A Puzzle about Belief," 248.

32 Ibid., 249.

${ }^{33}$ Searle, Intentionality, 257.
} 
From the sententionalist point of view, reporting the beliefs of historical figures includes stating the sentences these individuals believed to be true or false. Since replacing "Cicero" with "Tully" in "Cicero denounced Catiline" gives another sentence, the belief that the sentence about Cicero is true is a different belief from the belief regarding the sentence about Tully. However, the rejection of the disquotational principle has interesting consequences. We have seen that sententionalist history-writing fundamentally relies on the principle of translation, which defines when translations are allowed when reporting beliefs. For instance, "Aquinas believed that the soul is immortal" is true because "the soul is immortal" is a translation of the Latin sentence "anima immortalis est" that Aquinas believed to be true. But then it is unclear why we cannot say, in the above example, that it is true that "Tom believes that Tully denounced Catiline" when "Tully denounced Catiline" is a translation of "Cicero denounced Catiline," which Tom does believe to be true. We cannot merely rely on Tom's denial in order to establish his beliefs, since we have rejected the disquotational principle. Nor does it help to argue that the principle of translation allows translations only when the original statement is incomprehensible to the public the sentence is intended for-if this argument is invoked, one can easily proceed by constructing an imaginary situation in which the sentence is intended to report Tom's belief to a group of people who have heard of Tully, but not of Cicero. Once the disquotational principle is rejected and translations are allowed, sententionalist belief-reporting implies that if a person believes that a certain sentence is true, he or she also believes that any coreferential sentence is true as well.

\section{The intentionalist account of belief-reporting}

According to the intentionalist position too, if, in the part of the sentence that expresses the proposition believed to be true or false, we replace this articulation with the articulation of another proposition satisfied by the same intentional object (for example, an event), the sentence may change its truth value. For instance:

Tom believes that the greatest Roman orator denounced Catiline.

Tom believes that the author of De divinatione denounced Catiline.

decribe two different beliefs about the same intentional object: the content of the beliefs are two different propositions, which are fulfilled by different conditions of satisfaction-even though one and the same event happens to satisfy both of them.

Intentionalism assumes that propositions are independent of their verbal articulations, and that beliefs are always beliefs that some proposition is true or false. Consequently, a belief-reporting sentence will not change its truth-value if we replace the part of the sentence expressing the proposition believed to be true or false with another articulation of that same proposition. As Searle stated, when reporting beliefs, 
the reporter expresses the proposition which is the representative content of the believer's belief, but he need not be repeating any expression of belief, for the believer may never have expressed his belief. The reporter expresses the proposition which the believer believes, but in so doing he need not be repeating anything the believer has done. ${ }^{34}$

In other words, if, in the part of the sentence that reports a belief we replace a word or a phrase with a co-referential one: ${ }^{35}$

a) The sentence will not change its truth value if the new sentence expresses the same proposition;

b) The sentence may change its truth-value if the replacement of co-referential words and phrases results in a sentence expressing a different proposition.

This allows Skinner to say that "Milton believed that originality was important" while Milton himself would have used the term "things unattempted." Since the sentence "originality is important" expresses the same proposition as "trying things unattempted is important," the replacement of "trying things unattempted" with "originality" in the sentence reporting Milton's belief will not result in a sentence with a different truth value.

Similarly, Mark Bevir in his Logic of the History of Ideas imagines Ms. Patient, who belongs to a community in which the word "arthritis" is used for a rheumatoid disease of joints. ${ }^{36}$ She says "I have arthritis in my thigh" because she believes that she has a rheumatoid disease in her thigh and that the word "arthritis" refers to the rheumatoid disease of bones. In contrast to "hermeneutic occasionalists" Bevir uses this example to draw the distinction between intended and expressed meaning:

when she says "I have arthritis in my thigh," she intends to express the idea "I have a rheumatoid disease in my thigh," and anyone who so understands her will have correctly understood the hermeneutic meaning of her utterance. Hermeneutic occasionalists, in contrast, suggest that we would treat her utterance as an expression of the mistaken belief "I have arthritis in my thigh," and, more surprisingly, that she would accept our doing so. ${ }^{37}$

\footnotetext{
34 Searle, Intentionality, 188.

35 "As Frege was aware, in general, substitutions which preserve not only the same reference but also the same sense will preserve truth value even in intensional contexts: as long as the propositional content is preserved by the substitution, the truth value remains constant. But where two terms are ordinarily used to refer to the same object and the sense of the two is different, the substitution of one term for another can alter the content of the proposition and thus alter the truth value of the report." Searle, Intentionality, 193.

${ }^{36}$ Mark Bevir, The Logic of the History of Ideas (Cambridge, UK: Cambridge University Press, 1999), 64.

37 Ibid.
} 
It may seem, consequently, that in the example about Tom and Cicero, Bevir would have to say that Tom actually does believe that Tully denounced Catiline, and he merely does not know that the word "Tully" is used to refer to Cicero. "Tully denounced Catiline" is to be treated as just another articulation of the proposition expressed by "Cicero denounced Catiline" and, it may be argued on the intentionalist account, there should be no difference in truth value between the two sentences. Ultimately, it does not make sense to say:

\{Tom believes that [(someone denounced Catiline) and (that person's name was Cicero)] and (Tom's belief does not depend on any name of that person known to Tom).

In fact, the question is whether for Tom the proposition that we express using the sentence "Tully denounced Catiline" when reporting his beliefs, differs from the proposition that we convey using the sentence "Cicero denounced Catiline." The sentence is reporting the content of Tom's belief that the proposition expressed by "Tully denounced Catiline" is true or false. Sentences that report beliefs change their truth value when the words that report the content of the belief are replaced with co-referential ones, not because the words have been replaced, but because this replacement has made them report a different proposition that the person whose belief is reported does not believe to be true. Insofar as the sentences that result from such replacements express propositions whose satisfaction conditions are fulfilled by the same intentional object, the truth-value of belief-reporting sentences will change if the person whose beliefs are reported has contradictory beliefs regarding the truth-value of the propositions expressed by these sentences. It may also be the case that the person has never thought about the proposition the new sentence expresses, has no specific opinion about its truth, and therefore cannot be said to believe that it is true (or false)-in that case too, the belief-ascribing sentence will be false. Searle provides an example that pertains to a situation when the person whose belief is reported has contradictory beliefs: The Sheriff believes that Jesse James is a criminal and that Mr. Howard is an honest man; he does not know that Jesse James is the same person as Mr. Howard. If we now substitute "Jesse James" for "Mr. Howard" in

The Sheriff believes that Mr. Howard is an honest man.

we get a false sentence. Note that this is not merely because a proper name was replaced, but because, in the Sheriff's mind, the new sentence expresses a different proposition, one he does not believe to be true. The Sheriff believes that there exists a decent citizen who is named Mr. Howard and who is different from Jesse James. This character is, of course, fictional, and we know that Jesse James and Mr. Howard are one and the same person-but it is the Sheriff's belief that the sentence is reporting. When I report the Sheriff's belief about Mr. Howard, I use the proper name "Mr Howard" as the name for the fictional character in whose existence the Sheriff believes-or, more generally, for Jesse James in the role of a good citizen. 
Analogously with this example, one can say that in the case of reporting Tom's belief about Cicero and Tully, the important question is whether the sentence "Tully denounced Catiline" expresses a different proposition from "Cicero denounced Catiline," one Tom does not believe to be true. Tom may believe in the existence of a fictional historical character named "Tully" who is different from Cicero and who did not denounce Catiline. In that case, when reporting that he does not believe that Tully denounced Catiline, we are actually using "Tully" as the name of that fictional character. But if Tom has never heard of a man named "Tully," and does not believe that he denounced Catiline simply because he has no beliefs about him whatsoever, but at the same time believes that Cicero denounced Catiline, it is fair to say that he does believe that Tully denounced Catiline, although he does not know that Tully was Cicero's other name-the same way we would say that Milton believed that originality was important, without knowing that the word "originality" can be used for "trying things unattempted."

An important caveat is that, as we saw in the beginning, Searle's account of belief-reporting (as well as any other kind of linguistic acts) does not rely on communicative intention as one of its necessary aspects. Insofar as history is written with the intention to communicate, it is always important to make sure that the statement that conveys the content of a historical figure's beliefs accurately conveys to the public it is intended for the same proposition as the one that the historical figure believed to the true or false. If history-writing is to be understood, it often needs to provide the context that enables its own understanding. Take, for instance, the readers who know that Jesse James and Mr. Howard are the same person but who do not know that the Sheriff believed in the existence of Mr. Howard as a separate person. For them "Mr. Howard is an honest man" and "Jesse James is an honest man" express the same proposition (have the same conditions of satisfaction), but if a historian writes that the Sheriff believed that the first sentence is true, the readers may misunderstand him or her as saying that the Sheriff believed that the second is true as well. A belief-reporting sentence reports the conditions that a historical figure believed to be fulfilled, and readers in this case treat both sentences as expressing the same conditions of satisfaction. The Sheriff's belief that Mr. Howard is an honest man is, however, fulfilled by a completely different set of conditions, ones that pertain to the honesty of a fictional character named Mr. Howard. Belief-reporting in history-writing, if it is to be accurate, must take this into account and provide the necessary additional information.

\section{Conclusion}

This paper has demonstrated a number of clear advantages of the intentionalist position. History-writing in general, and the writing of intellectual history especially, depend massively on reporting the beliefs of historical figures who expressed them in languages other than the one in which the historian is writing. It is difficult to conceive how such history is possible without a credible explanation of what counts as legitimate translation for the purposes of such writing, and we have seen that the sententionalist position cannot provide this. The problem of translating recurs once again when it comes to explaining the problems the sententionalist position faces 
with substituting words and phrases in belief-reporting sentences for co-referential ones. At the same time, it has been shown that the intentionalist position easily overcomes all these problems. Searle's discussion of intentionality proves to be a valuable tool in resolving, in a simple and credible way, a number of standard problems of intentionalist history-writing, such as the status of its intentional objects. Nevertheless, mere differentiation between sententialist and intentionalist history-writing still leaves many other aspects of intentionalist history-writing unresolved. One important problem, closely related to the questions discussed here, pertains to the attribution of concepts to historical figures who did not have verbal means to express them. ${ }^{38}$ Some other problems that the intentionalist philosophy of history needs to address are, for instance, the attribution of unconscious beliefs, reporting the beliefs formulated within radically different conceptual frameworks, or the intentionality of beliefs about spatial and visual objects. Intentionalism is still far from being a fully defined way of writing history, even if it is to be preferred to sententionalism both in the philosophy of language and the philosophy of history. Or so this essay has sought to argue.

${ }^{38}$ See Prudovsky, "Can we ascribe" and Jouni-Matti Kuukkanen, "Making Sense of Conceptual Change", History and Theory, 47 (2008), 351-372. 